\title{
Glacier velocity variability due to rain-induced sliding and cavity formation
}

\author{
Huw J. Horgan ${ }^{a *}$, Brian Anderson ${ }^{a}$, Richard B. Alley ${ }^{b}$, Calum J. \\ Chamberlain $^{c}$, Robert Dykes ${ }^{d}$, Laura M. Kehrle ${ }^{e}$, John Townend ${ }^{c}$ \\ ${ }^{a}$ Antarctic Research Centre, Victoria University of Wellington, Kelburn Pde, \\ Wellington, New Zealand \\ ${ }^{b}$ Department of Geosciences and Earth and Environmental Systems Institute, The \\ Pennsylvania State University, University Park, Pennsylvania 16802 \\ ${ }^{c}$ Institute of Geophysics, Victoria University of Wellington, Kelburn Pde, Wellington, \\ New Zealand \\ ${ }^{d}$ Massey University, Palmerston North, New Zealand \\ ${ }^{e}$ Department of Earth and Space Sciences, University of Washington, Seattle, WA 98103, \\ $U S A$ \\ *huw.horgan@vuw.ac.nz
}

\begin{abstract}
The largest accelerations of glaciers and ice sheets are caused by changes in basal slip. Here we examine glacier speed and rain-induced accelerations using a near-continuous 26-month-long GNSS time series from a large maritime glacier (Tasman Glacier, New Zealand). During periods of high rain-rate we observe short-term increases in 24-hour speeds to up to 15-times background speed. Speeds calculated over 3-hour intervals increase to up to 36-times background speed. Acceleration events correspond with times when bed separation also increases rapidly indicating that the acceleration is associated with the growth of water-filled cavities at the bed. Glacier speeds then decrease prior to the reduction in bed separation, indicating cavity growth, not cavity extent, controls the acceleration. The short-term accelerations are superimposed on longer-term periods of enhanced velocity that persist for days to weeks and decay at similar rates to bed separation estimates and proglacial lake levels. A power-law relationship between observed rain-rate and speed exists at the glacier front and exhibits no apparent upper bound. Overall, we estimate that rain-induced accelerations account for $11-14 \%$ of Tasman
\end{abstract}


Glacier's displacement during the observation period. The rain-rate-velocity relationship and the rainfall record since 2001 indicate that rain-induced speed-up events result in interannual variability in glacier displacement of $3 \%-13 \%$.

Keywords: Glaciology, Subglacial Hydrology, Antarctica, Geophysics

\section{Introduction}

Mountain glaciers and ice caps are anticipated to contribute significantly to sea level rise over the coming century (Meier et al., 2007; Marzeion et al., 2012; Radic et al., 2014). There are two components to this contribution: changes in surface mass balance and changes in dynamics (e.g. accelerated flow, lake or tidewater calving). The potential for accelerated flow from glaciers and ice sheets has been highlighted as a major source of uncertainty in sea level rise predictions (IPCC, 2013, Chapter 10).

Predicting glacier behavior in a changing climate is complicated by the highly-variable contribution that basal sliding makes to overall glacier velocity. Basal sliding rates have the potential to change rapidly, and both theory and observational data have been used to establish a causal link between drag at the base of the glacier, water pressure and sliding velocity (Liboutry, 1968; Iken and Bindschadler, 1986; Bindschadler, 1983; Fowler, 1987; Schoof, 2005). When the glacier substrate is hard, the reduction in effective pressure caused by increasing basal water pressure has a direct effect on sliding velocity by reducing ice-bed contact and increasing zones of cavitation (Iken, 1981). When the glacier substrate is soft and deformable, reducing the effective pressure reduces the shear strength of the substrate (Clarke, 1987; Alley, 1989), and may result in enhanced sliding at the top of the substrate, and enhanced deformation at depths of decimeters to meters within the substrate (Fischer and Clarke, 2001; Truffer et al., 2000). Simple sliding laws relate sliding velocity $\left(u_{s}\right)$ to effective pressure $\left(P_{e}\right)$ at the glacier bed with $u_{s}=k \tau_{b}^{p} P_{e}^{-q}$, where $P_{e}=P_{i}-P_{w}, P_{i}$ and $P_{w}$ denote ice overburden pressure and basal water pressure respectively, $\tau_{b}$ denotes basal shear stress, and $k, p$, and $q$ are positive constants (e.g. Cuffey and Paterson, 2010). (Note that this form of unbounded sliding law implies that $u_{s}$ and $\tau_{b}$ can increase without limit.)

Despite this conceptual knowledge, predicting sliding velocities from effective pressure remains problematic. While observations generally support the 
relationship $u_{s}=f\left(\tau_{b}, P_{e}\right)$ (e.g. Iken and Bindschadler, 1986; Sugiyama and Gudmundsson, 2004; Sugiyama et al., 2011) significant issues remain. For example, hysteresis is often observed with identical effective pressures resulting in markedly different velocities. This hysteresis was demonstrated over short time intervals by Sugiyama and Gudmundsson (2004) who observed two distinct relationships between effective pressure and glacier speed depending on whether $P_{e}$ is increasing or decreasing. At longer time-scales, Iken and Truffer (1997) showed order-of magnitude differences in the speed of Findelengletscher, Switzerland, at similar driving stresses and effective pressures over a period of several decades. Further complexity in sliding relationships was demonstrated by Harper et al. (2007), in their study of subglacial water pressure and velocity at Bench Glacier, Alaska. Harper et al. (2007) documented two speed-up events, neither of which had an associated reduction in either local or regional $P_{e}$. Other researchers have sought to provide more realistic sliding laws (Iken, 1981; Schoof, 2005; Gagliardini et al., 2007) and have focussed on the lack of an upper limit to sliding velocity or basal shear stress implied by more simple laws. Nevertheless, the long-term contribution to glacier and ice sheet motion resulting from additional water inputs remains unclear (e.g. Zwally et al., 2002; Parizek and Alley, 2004; van de Wal et al., 2008; Sundal et al., 2011).

Here we present a high temporal resolution, 26 month-long record of the velocity of Tasman Glacier, South Island, New Zealand (Figure 1), and its response to rainfall events. Tasman Glacier is a large $\left(95 \mathrm{~km}^{2}\right.$; GLIMS and NSIDC, 2005) temperate glacier that contains approximately $29 \%$ of New Zealand's perennial ice (Chinn, 2001). The lower $10 \mathrm{~km}$ of Tasman Glacier is covered in debris (0-3 m thick, or greater, Kirkbride and Warren, 1999) and the glacier terminates in a proglacial lake that began to form in 1985 (Chinn, 1996) and covered $6.7 \mathrm{~km}^{2}$ by May 2013 (Figure 1). The lower Tasman Glacier has down-wasted at an average rate of $1.6 \mathrm{~m} \mathrm{a}^{-1}$ between 1891-2013 (Brodrick, 1891; Hart, 2014) and the terminus has retreated at an average rate of approximately $180 \mathrm{~m} \mathrm{a}^{-1}$ since lake inception. Thickness observations on Tasman Glacier are sparse. However, the glacier is known to be over-deepened, with a maximum water depth of $240 \mathrm{~m}$ in the proglacial lake (Dykes et al., 2011) and a maximum ice thickness of approximately $600 \mathrm{~m}$ at our upper station (Anderton, 1975). We report glacier velocity from three locations using continuous GNSS measurements. Our primary intention is to investigate the processes that govern glacier speed-up events and the contribution rain-induced speed-up events make to overall glacier 
motion. Our observations are notable due to the style and magnitude of the forcing (high rain rates), the magnitude of the response (large vertical and horizontal displacements), and the long continuous record obtained.

\section{Methods}

Two GNSS receivers spaced approximately $200 \mathrm{~m}$ apart and deployed within $500 \mathrm{~m}$ of the calving-front of Tasman Glacier (GPS1, GPS2 Figure 1) recorded at a 15 second sampling interval. GPS1 recorded from November 6th 2012 until January 26th 2015. GPS2 recorded from November 6th until July 27th, 2014. (Note all dates and times are referenced to UTC.) GPS1 and GPS2 provided essentially identical records, indicating that local phenomena such as crevassing are not affecting the records. In the analysis of velocity at the glacier front below we report only GPS1 data due to the longer duration of the record and the similarity of the two records. (GPS1 was shifted up-glacier during the deployment due to its proximity to the calving front. This offset and other minor adjustments were removed prior to velocity calculation.) A third receiver (GPS3) was located approximately $4.7 \mathrm{~km}$ up glacier and recorded from January 23rd until February 8th 2013 and from June 6th 2013 until January 26th 2015. The main data record for all stations is continuous with the exception of short periods of data loss due to heavy snowfall. The primary base station was also inoperable during October 2014, leading to an increased baseline length and degraded solutions. Receivers were placed on tripods approximately $1.6 \mathrm{~m}$ above the debris-covered glacier surface. The antennae were not fixed into the glacier due to the debris cover. Placement on the debris cover allowed for long-term deployments with minimal station servicing occurring approximately every 3 months but also means that the estimated position represents that of the glacier surface, not a fixed point within the glacier.

GNSS data were processed kinematically using differential carrier phase positioning (Chen, 1998). The base station was located on a fixed rock site approximately 10-15 km away from the glacier stations and sampled at 30 second intervals. Site motion was loosely constrained during kinematic processing to reduce noise without over smoothing. Velocities were calculated every hour using weighted linear regressions of all (30-second sampled) two-dimensional positions that fall within time intervals of 3-24 hours (Figure 2-4). Position weightings were determined from processing uncertainty estimates, which are primarily a function of satellite coverage. This scheme 
preserves the relative timing of minimum and maximum speeds (to the closest hour) but does smooth the velocity, resulting in earlier onset and delayed decay of speed-up events. Here we principally report speeds calculated over 24-hour periods (Figures 2, 3) and note that shorter periods result in significantly faster maximum velocities due to the relatively short durations of the velocity peaks (Figure 4). The relationship between the period over which velocity is calculated and peak velocity is not bounded, indicating we have not estimated the true maximum velocity of the glacier. Linear regression confidence limits show that $95 \%$ of the uncertainties for 24-hour velocities are less than $\pm 0.007 \mathrm{~m} \mathrm{~d}^{-1}$ and $99 \%$ are less than $\pm 0.02 \mathrm{~m} \mathrm{~d}^{-1}$.

Rainfall data are recorded hourly at Aoraki/Mt Cook Village $(11 \mathrm{~km}$ from Tasman Glacier terminus. $-43.736^{\circ}, 170.096^{\circ}, 765 \mathrm{~m}$ asl). While there are strong gradients in annual rainfall totals, the timing of rainfall events is generally uniform in the central Southern Alps (Henderson and Thompson, 1999). Hourly automatic weather station observations began at Aoraki/Mt Cook Village in March 2000, prior to which daily manual observations are available back to 1928 .

No direct observations of effective pressure at the glacier sole are available but lake level observations were made near the proglacial lake outlet (Figure 1) using a Hobo pressure transducer with data logged at 15 minute intervals until April 16th 2013. These data were corrected for air pressure variations using hourly data from Aoraki/Mt Cook Village. This sensor was replaced on November 18th, 2013, with an atmospherically-coupled pressure transducer with data logged at 1 minute intervals.

\section{Results}

\subsection{GNSS positions and velocities}

The surface elevations of the GNSS stations show a gradual secular decrease in elevation which is the result of glacier thinning and advection. This slow rate of lowering is interspersed with rapid ( $<24$-hour) increases in elevation coinciding with periods of high rain rate. Following the cessation of rainfall, surface elevation initially reduces more quickly than the background rate, but approaches the background rate over a period of weeks. The duration of this recovery is dependent on the magnitude of the rain event (Figure 2,3). The largest of these vertical offsets occurred on January 1st-2nd 2013 and resulted in a vertical offset of $0.56 \pm 0.02 \mathrm{~m}$ over a 24 hour period at GPS1 (Figure 3). GPS3 shows greater vertical offset during rainfall 
events than the front two stations (Figures 2, 3). GPS3 was not, however, operating during the largest rainfall events in late 2012-early 2013. We examine the factors contributing to surface elevation in more detail in the bed separation analysis below.

Glacier horizontal speeds $\left(u_{\text {observed }}\right)$ exhibit variability at multiple temporal scales. Short-term speed-up events are observed at numerous times throughout the record. Figures 2a-c show seventeen speed-up events exceeding $0.4 \mathrm{~m} \mathrm{~d}^{-1}$ in the 26 month period recorded by GPS1. Peak 24-hour speeds reach $2.03 \mathrm{~m} \mathrm{~d}^{-1}$ at the front stations on January 1st 2013 with the second largest speed-up event occurring on January 9th 2013. Calculating speed over shorter time intervals leads to a peak speed of $4.45 \mathrm{~m} \mathrm{~d}^{-1}$ from 3-hour intervals on January 9th 2013, approximately 36 times that prior to the speed-up event (Figure 4). Up-glacier, GPS3 shows a similar velocity pattern to the front GNSS stations but with a greater background velocity and higher speed-up velocities. During its shorter observation period, GPS3 exhibits nineteen speed-up events exceeding $0.4 \mathrm{~m} \mathrm{~d}^{-1}$. The GPS3 speed-up events precede the front GPS stations by approximately 3 hours (Figure 3). The record also demonstrates seasonal speed variability with the background glacier speed reaching a minimum during July-August (austral winter) and a background level maximum during January-February (Figure 5).

To estimate the background speed ( $u_{\text {background }}$ ) we first remove 7-day asymmetric windows around all speed-up events exceeding $0.4 \mathrm{~m} \mathrm{~d}^{-1}$ (Figure 5). The edited window period starts one day prior to and ends six days after the peak speed. The remaining data show an annual sinusoidal velocity variation combined with a linear acceleration. Positive excursions from this pattern represent unedited speed-up events, while negative excursions (and some positive excursions) likely represent erroneous position and velocity estimates not captured in our formal uncertainty estimates. To enable later estimates of the contribution of speed-up events to overall glacier displacement, we fit the edited velocity time-series with the function $u_{\text {background }}(t)=a \sin (\omega t+\phi)+b t+c$ where $t$ denotes time, the frequency $\omega$ is set to a one-year period, and the fitting constants $(a, \phi, b$, and $c)$ are optimized. The coefficient of determination $\left(\mathrm{R}^{2}\right)$ of the raw data against the fitted function is low $\left(\mathrm{R}_{G P S 1}^{2}=0.25, \mathrm{R}_{G P S 3}^{2}=0.35\right)$, which is expected as short-term variability in the record cannot be captured by the low-frequency function. When two-weekly average velocities are compared the $\mathrm{R}^{2}$ increases to 0.59 and 0.69 for GPS1 and GP3 respectively. These two-weekly averages are more representative of seasonal variability. 
The amplitude $(a)$ of the fitted $u_{\text {background }}(t)$ for GPS1 indicates a seasonal speed variability of $0.0281 \pm 0.0003 \mathrm{~m} \mathrm{~d}^{-1}$ (peak-trough) $(10.27 \pm 0.13 \mathrm{~m}$ $\mathrm{a}^{-1}$ ) while the linear function's gradient implies a background acceleration of $0.000020 \pm 0.000001 \mathrm{~m} \mathrm{~d}^{-2}\left(2.60 \pm 0.14 \mathrm{~m} \mathrm{a}^{-2}\right)$. Error estimates indicate the $2 \sigma$ fitting uncertainty. For GPS3, the seasonal speed variability is $0.0243 \pm 0.0004$ $\mathrm{m} \mathrm{d}^{-1}$ (peak-trough) $\left(8.85 \pm 0.15 \mathrm{~m} \mathrm{a}^{-1}\right)$ and the linear function's gradient implies a background acceleration of $0.000035 \pm 0.000002 \mathrm{~m} \mathrm{~d}^{-2}(4.62 \pm 0.23$ $\mathrm{m} \mathrm{a}^{-2}$ ). Allowing $\omega$ to also be optimized results in an optimal period of $347 \pm 1$ day for GPS1 and $362 \pm 6$ days for GPS3. This slightly increases the 2 -weekly $\mathrm{R}^{2}$ to 0.63 and 0.72 respectively. In our subsequent analysis we use the one-year fits, as this is the expected period.

To examine the speed-up events in more detail, all periods where speed exceeded $0.4 \mathrm{~m} \mathrm{~d}^{-1}$ for GPS1 and GPS3 are extracted and aligned in Figure 6. The characteristics of events is generally uniform with a rapid onset and decay. Close inspection shows that after the initial speed-up event has passed, the speed remains at an elevated level. This is more obvious for the two largest events recorded by GPS1, but is also true for the smaller events.

\subsection{Rainfall}

Automatic weather station data from Aoraki/Mt Cook Village show high rates of rain with peak rain rates of $38 \mathrm{~mm} \mathrm{hr}^{-1}$ (January 9th, 2013) and 353 $\mathrm{mm} \mathrm{d}^{-1}$ (January 1st, 2013). During the observation period, there were 22 days on which rainfall exceeded $100 \mathrm{~mm}$. During 2013 and 2014 cumulative rainfall at Aoraki/Mt Cook totaled $4.52 \mathrm{~m}$ and $4.55 \mathrm{~m}$ respectively (Figure 2).

\subsection{Rainfall-velocity relationship}

Rainfall and the speed of Tasman Glacier exhibit an obvious visual correlation (Figure 2,3). To investigate this correlation, we first extracted fourday windows around all speed-up events that exceeded a threshold value of $0.4 \mathrm{~m} \mathrm{~d}^{-1}$. We then cross-correlated the resulting rain-rate $(W)$ and velocity subsets to determine peak correlation lags. (Our results are largely insensitive to our window interval; however, too small an interval can fail to catch the causative rainfall event and too large an interval can lead to the inclusion of multiple events.) For cross-correlation, we use velocity calculated over 24hour intervals and a 24-hour running mean of the hourly rain rate record. We discard velocity-rainfall pairs where the Pearson correlation coefficient is $\leq$ 0.1 and then lag-adjust the rain-rate data. The correlation-coefficient-based editing preserves eleven of 17 speed-up events at GPS1 and 17 of 19 events at 
GPS3. Cross correlation coefficients at GPS1 average 0.50 with a standard deviation of 0.22 , while GPS3 averages 0.52 with a standard deviation of 0.20 . The average lag-time for peak cross-correlation averages 9.4 hours at GPS1 and 8.5 hours at GPS3.

The relationship between rain-rate and lagged speed is shown in Figure 7 . GPS1 exhibits a power-law relationship $u_{\text {speedup }}=d W^{e}+f$, where $u_{\text {speedup }}$ denotes glacier speed $\left.\left(\mathrm{m} \mathrm{d}^{-1}\right)\right)$ and $W$ denotes smoothed rain-rate $\left(\mathrm{mm} \mathrm{hr}^{-1}\right)$, and $d, e$, and $f$ are constants whose values are determined by minimizing the difference between the function and the data. The $\mathrm{R}^{2}$ for the fit of GPS1 is 0.77. (Best fitting constants and 2-sigma fitting uncertainties are : $d_{G P S 1}=0.005 \pm 0.002, e_{G P S 1}=2.18 \pm 0.146$, and $\left.f_{G P S 1}=0.214 \pm 0.014\right)$. For GPS3 the relationship between rain rate and lagged speed does not show the same pattern and is equally well fit $\left(\mathrm{R}^{2}=0.55\right)$ by a power-law as by a linear function where $u=d W+f$. (The best fitting linear function for GPS3 has coefficients $d_{G P S 3}=0.085 \pm 0.004$, and $f_{G P S 3}=0.207 \pm 0.012$.)

\subsection{Speed-up contribution to overall displacement}

To estimate the contribution speed-up events make to the overall displacement of Tasman Glacier we use two methods. Within the period of observation (GPS1: $t_{0}=$ November 7 2012, $t_{1}=$ January 26 2015. GPS3: $t_{0}$ $=$ June $6,2013, t_{1}=$ January 26, 2015.) we estimate the speed-up contribution to displacement $\left(x_{\text {rain }}\right)$ by differencing the observed displacement and the seasonally varying contribution estimated in Section 3.1:

$$
x_{\text {rain }}=\int_{t_{0}}^{t^{1}} u_{\text {observed }}(t)-u_{\text {background }}(t) \mathrm{d} t
$$

where $u_{\text {observed }}(t)$ is our observed speed time-series and the background speed is a best fitting function $a \sin (\omega t+\phi)+b t+c$ (Section 3.1.). Using Equation 1 we estimate that speed-up events accounted for approximately $11 \pm 4 \%$ of the overall glacier displacement during the period of observation at GPS1 and $14 \pm 4 \%$ up-glacier at GPS3. (Uncertainties obtained from minimum and maximum fitting constraints.)

An estimate of interannual variability and the longer-term contribution to glacier displacement due to rain-induced sliding can be obtained from the entire hourly rainfall record for Aoraki/Mt Cook (beginning March 29 2000) and a combination of the best fitting functions for seasonal velocity (Section 3.1, Figure 5) and the best fitting rain-rate-speed functions (Section 3.3, Figure 7). These estimates are not intended as a hindcast, as they 
assume that the processes governing rain-induced speed-up events at present have existed in their current form in the past. Instead we take the rainfall observations as an estimate of the interannual variability in rainfall in the region, and use this to estimate an expected range of interannual displacement variability.

Using the seasonal velocity and the rainfall-velocity relationships, a synthetic glacier speed record $\left(u_{\text {syn }}\right)$ can be estimated using:

$$
u_{\text {syn }}(t)= \begin{cases}a \sin (\omega t+\phi)+c & : W<=W_{\text {threshold }} \\ d W^{e}+f & : W>W_{\text {threshold }}\end{cases}
$$

(Note that here we exclude the $b t$ term, detrend the observations, and obtain new fitting parameters so as to avoid negative displacements in the past.) The additional displacement due to speed-up events can then again be estimated using Equation 1 by substituting Equation 2 for our observed velocity time series. This method requires a rain-rate threshold ( $\left.W_{\text {threshold }}\right)$, above which rain-induced sliding is expected to occur. We determine a threshold smoothed rain-rate of $3.2 \mathrm{~mm} \mathrm{hr}^{-1}$ by minimizing the difference between the velocity estimated using Equation 2 and station speed observed during the study period $\left(u_{\text {observed }}\right)$. (Examining Figure 7 also shows that a threshold in this range is appropriate.) Using this threshold and Equation 2, we estimate that at GPS1 (the glacier front) $6 \%$ of the overall displacement during the entire rainfall record was due to rain-induced speed-up events. Up-glacier at GPS3 the overall displacement due to speed-up events was $7 \%$ of the total. Examining each full calendar year (2001-2014) indicates a minimum contribution of $2 \%$, a maximum of $13 \%$, and an average of $6 \pm 4 \%$ ( 1 standard deviation) at GPS1 and a minimum contribution of $3 \%$, a maximum of $13 \%$, and an average of $7 \pm 3 \%$ (1 standard deviation) at GPS3.

\subsection{Surface elevation and bed separation}

Our surface elevation record contains information on the processes taking place at the glacier bed, which are thought to result in the observed speedup events. To quantify the amount of vertical bed separation occurring as a result of cavity formation at the glacier bed, we follow the analyses of Iken and Bindschadler (1986), Harper et al. (2007) and Howat et al. (2008). Surface elevation $(z)$ change with respect to time is the sum of bed separation $(s)$ change with respect to time, elevation change due to advection at velocity $u$ along bed slope $\beta$ and depth-averaged vertical strain rate $\left(\left\langle\dot{\epsilon}_{z z}\right\rangle\right)$ of the mean ice thickness $H$ : 


$$
\frac{d z}{d t}=\frac{d s}{d t}+u \tan \beta+\left\langle\dot{\epsilon}_{z z}\right\rangle H
$$

Here we do not account for changes due to sediment dilation and surface ablation. Quantifying the effect of sediment dilation, as pointed out by Howat et al. (2008), requires borehole observations and is unlikely to generate displacements greater than the order of $\mathrm{mm}$ per day. Changes in surface elevation due to ablation can be more significant; however, neglecting surface ablation will only reduce our estimates of bed separation. Furthermore, short-period ablation changes are unlikely given the debris cover which buffers the underlying ice surface against short-term energy balance changes.

We calculate bed separation for the midpoint between GPS1 and GPS3. Average velocity and elevation time-series are used and the interval over which bed separation is calculated is reduced to the 18-month record of GPS3 (Figure 8). We note that our large station spacing (approximately 16 times ice thickness), and our assumption that vertical strain rates are uniform for the full ice thickness, make our bed separation estimates indicative only. (See Mair et al., 2002, for a discussion of the influence of observation spacings on quantitative estimates of bed separation). Vertical strain rate is estimated using the continuity equation $\left(\dot{\epsilon}_{z z}=-\left(\dot{\epsilon}_{x x}+\dot{\epsilon}_{y y}\right)\right)$ and following Howat et al. (2008). The glacier geometry is defined by three perpendicular axes, $x, y, z$, which are along-flow, across-flow, and vertical respectively. Positive strain rates are extensional, while negative represent compression. The along-flow strain rate $\dot{\epsilon}_{x x}$ is estimated from the station displacements $\left(\dot{\epsilon}_{x x}=\frac{\Delta L}{L \Delta t}\right)$ under the assumption that GPS1 and GPS3 lie on a flow line and are separated by distance $L$. The absence of a triangular network of stations necessitates the estimation of the transverse strain-rate component from the glacier width gradient, whereby

$$
\dot{\epsilon}_{y y}=\frac{\langle u\rangle}{W} \frac{\mathrm{d} W}{\mathrm{~d} x}
$$

(Van der Veen, 1999). (The width $(W)$ gradient is determined from LandSat imagery (Figure 1) along a $3.3 \mathrm{~km}$ flow line from GPS3 towards the glacier front. Average velocity $(\langle u\rangle)$ is determined from the average of GPS1 and GPS3.) We estimate a mean thickness $(H)$ of $270 \mathrm{~m}$ using a variation of the mass flux method of Farinotti et al. (2009) (Anderson et al., 2015).

The $u \tan \beta$ component of the bed separation estimate amounts to approximately $0.02 \mathrm{~m}$ during a typical speed up event, while the $\left\langle\dot{\epsilon}_{z z}\right\rangle H$ component amounts to a similar $0.02 \mathrm{~m}$. Both of these contributions are positive 
during speed up events so they detract from our estimated bed separation. Uncertainty in $\dot{\epsilon}_{y y}$ could result in the following. In the case of a $\dot{\epsilon}_{y y}$ other than that calculated from the width gradient method, a linear trend would be introduced in our bed separation estimate. In the case of a time-variant $\dot{\epsilon}_{y y}$, such as that indicated by observations of transverse divergence during speed-up events (Sugiyama et al., 2010), our estimates of $\left\langle\dot{\epsilon}_{z z}\right\rangle$ will be too small, and our resulting estimates of bed separation $(s)$ will be too large. Overall, our $\left\langle\dot{\epsilon}_{x x}\right\rangle$ estimates are an order of magnitude larger than our $\left\langle\dot{\epsilon}_{y y}\right\rangle$ estimate making methodological uncertainties in $\left\langle\dot{\epsilon}_{y y}\right\rangle$ acceptable. Finally we remove a low-order spline from our bed separation estimate, to account for the long-period signal related to uncertainties in bed slope and surface ablation (Figure 8), and fix the lowest bed separation value to zero. Aligned bed separation estimates are shown with corresponding speed-up events and lake level in Figure 9.

\section{Discussion}

Tasman Glacier exhibits some of the largest short-term accelerations reported in the literature. The speed of Tasman Glacier also exhibits no apparent upper bound within the observation period (Figure 7). Glacier minimum and maximum surface velocities are, however, certain to have an asymptotic relationship with effective pressure. The lower limit should represent ice speed resulting from ice deformation, regelation-enabled slip, and enhanced creep with no contribution from enhanced basal slip. The upper velocity limit is obtained when effective pressure leads to complete bed separation, and the glacier driving stress is balanced primarily by lateral drag at the glacier walls and longitudinal stress gradients. (For a thorough discussion see Cuffey and Paterson (2010).) The large magnitudes of the speed-up events on Tasman Glacier are likely the result of the high rain rates of up to $38 \mathrm{~mm} \mathrm{hr}^{-1}$ and $353 \mathrm{~mm} \mathrm{~d}^{-1}$. This peak hourly rain rate is comparable to peak daily rates in other settings (e.g. Howat et al., 2008). It is worth noting that the rain rates during the observation period at Aoraki/Mt Cook are not unprecedented as rates have exceeded $300 \mathrm{~mm} \mathrm{~d}^{-1}$ on 13 days since daily records began in 1928, and twice exceeding $500 \mathrm{~mm} \mathrm{~d}^{-1}$.

The initial speed-up events are short in duration, lasting around 24 hours (Figure 6). This duration decreases significantly when speed is calculated over shorter intervals (Figure 4). After the rapid increase and rapid decline, glacier speed does, however, remain above background levels, decaying to 
background levels over a similar duration as both bed separation and lake level (Figure 9). This more gradual decline is easily apparent for the largest speed-up events presented in Figure 6. Peak speeds precede peak bed separation and instead correspond with rapidly increasing bed separation (Figure 9). This is akin to the correspondence of peak horizontal and vertical velocity noted by Iken and Bindschadler (1986). Both peak speed and peak bed-separation precede peak lake level. Speed initially decays much faster than either bed separation or lake level, which both decay at similar rates.

It is likely that we are observing linked processes occurring on two timescales; an initial high-amplitude acceleration that is associated with the growth of cavities, and a longer-term period of enhanced velocity-anomaly associated with the existence of said cavities. The initial acceleration is akin to ratcheting the glacier forwards. Cavitation moves the glacier up and forwards, and the following cavity collapse has no corresponding opposite horizontal motion. The short-term increase in speed associated with cavity growth would be accompanied by a sudden drop in effective pressure caused by the high rain-rates. Cavity growth would then cause a reduction in water pressure (increase in effective pressure) and a rapid decrease in velocity would be expected at the cessation of cavity growth. It is difficult to discriminate between the speed contribution made by the formation of cavities and the reduction in effective pressure due to these two processes being temporally coincident and intrinsically linked. The proportions of horizontal and vertical motion associated with cavity growth will be dictated by the cavity shape and viscoelastic ice response. (For analytical and numerical examples see Schoof (2005) and Gagliardini et al. (2007) respectively.)

The glacier front (GPS1) and up-glacier station (GPS3) exhibit different rain-rate-speed relationships. At the glacier front the relationship between lagged rain-rate and speed (Figure 7) is functionally similar to the simple sliding laws commonly used in glaciology $\left(u(W)=d W^{e}+f\right.$ versus $u_{s}=$ $k \tau_{b}^{p} P_{e}^{-q}$ ), implying that rain-rate may correlate well with water pressure. Up glacier, the relationship is less clear with a linear relationship fitting the data equally as well as a power-law $\left(\mathrm{R}^{2}=0.55\right)$. The upper site shows greater scatter but exhibits the same optimal rain-rate threshold required for speedup events. We note that the actual thresholds are likely to vary due to our use of the Aoraki/Mt Cook automatic weather station and our failure to account for rain-rate gradients between the glacier front and up-glacier site. The functional difference in the rain-rate-speed-up relationship at the glacier front and further up glacier may be due to the proglacial lake. We dismiss 
lake-level as the primary driver of the speed-up events due to the phasing of the speed-up events (the upper glacier speeds up before the lower glacier). Cross correlation of speed up events and lake-level rate of change produces negative peak correlation lags for 6 of the 17 speed up events at GPS1 and 12 of the 19 speed-up events at GPS3, indicating that in these cases the speed up events preceded the lake level increases. However, the proximity of the front stations make some connectivity between their underlying subglacial drainage system and the lake likely. Such connectivity would mean changes in lake level would cause changes in effective pressure at the glacier bed.

Changes in the subglacial drainage system are often invoked to explain the complex relationship between water inputs and sliding speed as low subglacial water flux can be accommodated in a high-pressure distributed network (Fountain and Walder, 1998), while high fluxes promote the development of a lower pressure concentrated system (Röthlisberger, 1972; Fountain and Walder, 1998). This means that a range of possible sliding velocities can result from the same water flux and reinforces the notion that water input variability is important in addition to subglacial water flux (e.g. Schoof, 2010; Bartholomaus et al., 2008; Kehrl et al., 2015). Understanding the causal relationship between rain-rate and velocity is further complicated by the need to cross-correlate and lag the two time series. Ideally our observations would include water pressure at the glacier bed. As direct observations of water pressure are unavailable we instead look to the vertical record provided by our stations and use this record to estimate bed separation. Bed separation is expected to scale with fractional coverage of cavities at the bed (Alley, 1989) and it is informative to examine the relationship between bedseparation and speed (e.g. Howat et al., 2008). Figure 10 demonstrates the hysteresis in this relationship. For each event horizontal speed undergoes a large increase during the initial increase in bed separation. Horizontal speed then plateaus while bed separation continues to increase. A rapid decline in horizontal speed then corresponds with the peak in bed separation. This peak in bed separation marks the end of the direct contribution to horizontal speed caused by cavity growth.

Rainfall events on Tasman Glacier result in an overall increase in glacier motion, and contribute to the interannual variability observed in the glacier's velocity (e.g. Redpath et al., 2013). During the observation period 11-14\% of the glacier's displacement was due to rain-induced sliding. Treating the rainfall record between 2001-2014 (inclusive) as representative of the interannual variability in the forcing, we estimate that rain-induced speed-up events are 
likely to have a positive contribution to displacement of between $3 \%-13 \%$ per annum. While the high rain-rates occurring at Tasman Glacier are unlikely to apply to many glaciers, the resulting processes are likely to be widely applicable.

\section{Conclusions}

During times of high rain-rate Tasman Glacier exhibits short-term accelerations to up to 15 times its background velocity calculated over 24-hour intervals and 36 times its background velocity calculated over 3-hour intervals. During the period of observation, the relationship between rain rate and horizontal speed exhibits no apparent upper bound, and rain-induced accelerations result in 11-14\% of the overall glacier displacement. Using estimates of background and rain-rate dependent velocity, the interannual variability of displacement resulting from rain events is estimated to range between $3 \%$ and $13 \%$ of total displacement. The observed speed-up events, which greatly expand the range of rain-induced acceleration reported in the literature, are thought to result from two-stages of enhanced velocity; an initial short-term acceleration associated with cavity growth and a longer-term velocity anomaly that decreases at a similar rate to cavity size.

\section{Acknowledgments}

This study was supported by a Victoria University of Wellington Research Establishment Grant and a Faculty Strategic Research Grant, as well as the New Zealand Marsden Fund. RBA acknowledges NSF 0424589. We thank Ružica Dadić for helpful discussions. We also thank for two anonymous reviewers for their detailed and constructive comments.

\section{References}

Alley, R. B., 1989. Water-pressure coupling of sliding and bed deformation: I. water system. J. Glaciol. 35 (119), 108-118.

Anderson, B. A., Mackintosh, A. N., Oerlemans, J., Mullan, B., Zammit, C., Sood, A., Doughty, A., Dadic, R., 2015. Modeled response of debriscovered and lake-calving glaciers to warming, Southern Alps, New Zealand. In prep. 
Anderton, P. W., 1975. Tasman glacier 1971-73. Tech. Rep. 33, Ministry of Works and Development.

Bartholomaus, T. C., Anderson, R. S., Anderson, S. P., 01 2008. Response of glacier basal motion to transient water storage. Nature Geosci 1 (1), 33-37.

URL http://dx.doi.org/10.1038/ngeo.2007.52

Bindschadler, R. A., 1983. The importance of pressurized subglacial water in separation and sliding at the glacier bed. Journal of Glaciology 29 (101), 3-19.

Brodrick, 1891. Map of Tasman and Murchison Glaciers. Government Survey, deposited with the Christchurch office of Land Information New Zealand (LINZ).

Chen, G., 1998. GPS kinematics positioning for airbourne laser altimetry at Long Valley. Ph.D. thesis, Massachusetts Institute of Technology.

Chinn, T., 2001. Distribution of the glacial water resources of new zealand. Journal of Hydrology (NZ) 40 (2), 139-187.

Chinn, T. J., 1996. New zealand glacier responses to climate change of the past century. New Zealand Journal of Geology and Geophysics 39, 415-428.

Clarke, G. C. K., Aug. 1987. Subglacial till: a physical framework for its properties and processes. J. Geophys. Res. 92 (B9), 9023-9036.

Cuffey, K. M., Paterson, W. S. B., 2010. The Physics of Glaciers, 4th Edition. Elsevier.

Dykes, R., Brook, M., Robertson, C., Fuller, I., Feb. 2011. Twenty-first century calving retreat of tasman glacier, southern alps, new zealand. Arctic, Antarctic, and Alpine Research 43 (1), 1-10.

URL http://dx.doi.org/10.1657/1938-4246-43.1.1

Farinotti, D., Huss, M., Bauder, A., Funk, M., Truffer, M., 2009. A method to estimate the ice volume and ice-thickness distribution of alpine glaciers. Journal of Glaciology 55 (191), 422-430.

URL http://www . ingentaconnect. com/content/igsoc/jog/2009/00000055/00000191/art0 
Fischer, U. H., Clarke, G. K. C., 2001. Review of subglacial hydro-mechanical coupling: Trapridge Glacier, Yukon Territory, Canada. Quaternary International 86, 29-43.

Fountain, A. G., Walder, J. S., 1998. Water flow through temerate glaciers. Reviews of Geophysics 36 (3), 299-328.

Fowler, A. C., 1987. Sliding with cavity formation. Journal of Glaciology 33 (115), 255-267.

Gagliardini, O., Cohen, D., Raback, P., Zwinger, T., 2007. Finite-element modeling of subglacial cavities and related friction law. Journal of Geophsyical Research 112 (F02027), 1-11.

GLIMS, NSIDC, 2005. Glims glacier database. Tech. rep., GLIMS and National Snow and Ice Data Center, Boulder, Colorado USA.

Harper, J. T., Humphrey, N. F., Pfeffer, W. T., Lazar, B., 2007. Two modes of accelerated glacier sliding related to water. Geophys. Res. Lett. 34 (L12503), 1-5.

Hart, R., 2014. The ice thickness distribution of a debris covered glacier: Tasman glacier, new zealand. Master's thesis, Victoria University of Wellington.

Henderson, R. D., Thompson, S. M., 1999. Extreme rainfalls in the Southern Alps of New Zealand. Journal of Hydrology (NZ) 38, 309-330.

Howat, I. M., Tulaczyk, S., Waddington, E. D., Björnsson, H., 2008. Dynamic controls on glacier basal motion inferred from surface ice motion. J. Geophys. Res. 113 (F03015), 1-15.

Iken, A., 1981. The effect of the subglacial water pressure on the sliding velocity of a glacier in an idealized numerical model. Journal of Glaciology 27 (97), 407-421.

Iken, A., Bindschadler, R. A., 1986. Combined measurements of subglacial water pressure and surface velocity of Findelengletscher, Switzerland: Conclusions about drainage system and sliding mechanism. Journal of Glaciology 32 (110), 101-119. 
Iken, A., Truffer, M., 1997. The relationship between subglacial water pressure and velocity of Findelengletscher, Switzerland, during its advance and retreat. Journal of Glaciology 43 (144), 328-338.

IPCC, A., 2013. Climate change 2013: The physical science basis. In: Contribution of Working Group I (WGI) to the Fifth Assessment Report (AR5) of the Intergovernmental Panel on Climate Change (IPCC). Cambridge University Press.

URL http://www.ipcc.ch/report/ar5/wg1/

Kehrl, L. M., Horgan, H. J., Anderson, B. A., Dadic, R., Mackintosh, A. N., 2015. Glacier velocity and water input variability in a maritime environment: Franz Josef Glacier, New Zealand. Journal of Glaciology 61 (228), 663:674.

Kirkbride, M. P., Warren, C. R., 1999. Tasman Glacier, New Zealand: 20thcentrury thinning and predicted calving retreat. Global and Planetary Change 22, 11-28.

Liboutry, L., 1968. General theory of subglacial cavitation and sliding of temperate glaciers. Journal of Glaciology 7 (49), 21-58.

Mair, D. W. F., Sharp, M. J., Willis, I. C., 2002. Evidence for basal cavity opening from analysis of surface uplift during a high-velocity event: Haut Glacier d'Arolla, Switzerland. Journal of Glaciology 48 (161), 208-216.

Marzeion, B., Jarosch, A. H., Hofer, M., Aug. 2012. Past and future sea-level change from the surface mass balance of glaciers. The Cryosphere Discuss. 6 (4), 3177-3241. URL http://www.the-cryosphere-discuss .net/6/3177/2012/

Meier, M. F., Dyurgerov, M. B., Rick, U. K., O’Neel, S., Pfeffer, W. T., Anderson, R. S., Anderson, S. P., Glazovsky, A. F., 2007. Glaciers dominate eustatic sea-level rise in the 21st century. Science 317, 1064-1067.

Parizek, B. R., Alley, R. B., 2004. Implications of increased Greenland surface melt under global-warming scenarios: ice-sheet simulations. Quaternary Science Reviews 23 (9-10), 1013-1027.

Radic, V., Bliss, A., Beedlow, A. C., Hock, R., Miles, E., Cogley, J. G., Jan. 2014. Regional and global projections of twenty-first century glacier 
mass changes in response to climate scenarios from global climate models. Climate Dynamics 42 (1-2), 37-58. URL http://www . diva-portal .org/smash/record. jsf?pid=diva2: 685564

Redpath, T. A. N., Sirguey, P., Fitzsimons, S. J., Kääb, 2013. Accuracy assessment for mapping glacier flow velocity and detecting flow dynamics from ASTER satellite imagery: Tasman Glacier, New Zealand. Remote Sensing of Environment 133, 90-101.

Röthlisberger, 1972. Water pressure in intra- and subglacial channels. Journal of Glaciology 11 (62), 177-203.

Schoof, C., 2005. The effect of cavitation on glacier sliding. Proceedings of the Royal Society 461, 609-627.

Schoof, C., 2010. Ice-sheet acceleration driven by melt supply variability. Nature 468, 803-806.

Sugiyama, S., Bauder, A., Riesen, P., Funk, M., 2010. Surface ice motion deviating toward the margins during speed up events at Gornergletscher, Switzerland. Journal of Geophsyical Research 115 (F03010), 1-12.

Sugiyama, S., Gudmundsson, G. H., 2004. Short-term variations in glacier flow controlled by subglacial water pressure at Lauteraargletscher, Bernese Alps, Switzerland. Journal of Glaciology 50 (170), 353-362.

Sugiyama, S., Skvarca, P., Naito, N. an dEnomoto, H., Tsutaki, S. an dTone, K., Marinsek, S., Aniya, M., 2011. Ice speed of a calving glacier modulated by small fluctuations in basal water pressure. Nature Geoscience 4, 597600 .

Sundal, A. V., Shephard, A., Nienow, P., Hannah, E., Palmer, S., Huybrechts, P., 2011. Melt-induced speed-up of Greenland ice sheet offset by efficient subglacial drainage. Nature 469, 521-524.

Truffer, M., Harrison, W. D., Echelmeyer, K. A., 2000. Glacier motion dominated by processes deep in underlying till. Journal of Glaciology 46 (153), 213-221.

van de Wal, R. S. W., Boot, W., van den Broeke, M. R., Smeets, C. J. P. P., Reijmer, C. H., Donker, J. J. A., Oerlemans, J., 2008. Large and rapid 
585 melt-induced velocity changes in the ablation zone of the Greenland Ice 586 Sheet. Science 321, 111-113.

${ }_{587}$ Van der Veen, C. J., 1999. Fundamentals of glacier dynamics. A.A. Balkema. ${ }_{588}$ Zwally, H. J., Abdalai, W., Herring, T., Larson, K., Saba, J., Steffen, K., 589 2002. Surface melt-induced acceleration of Greenland Ice-Sheet flow. Sci$590 \quad$ ence 297 (5579), 218-221. 


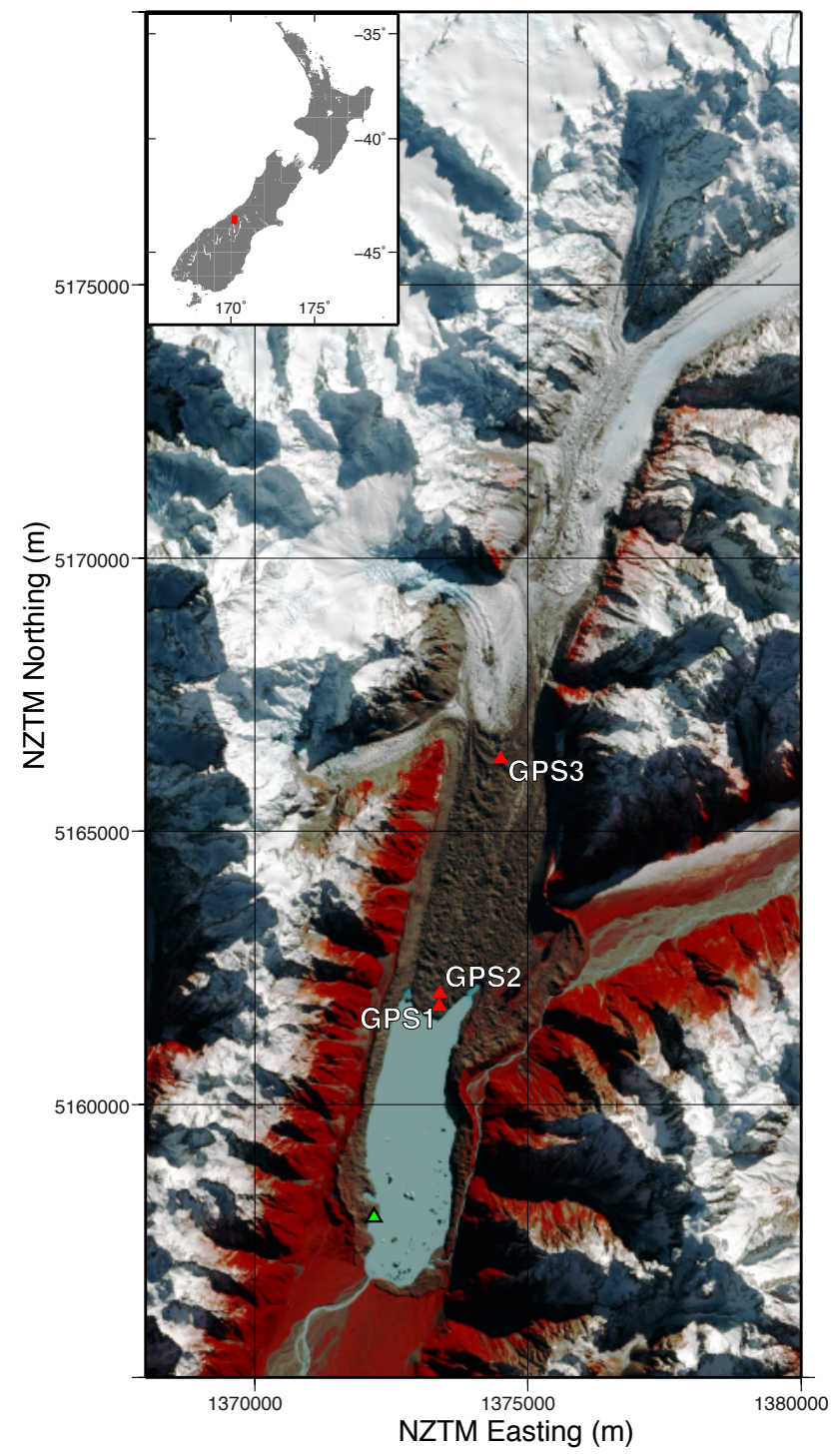

Figure 1: Pansharpened Landsat-8 false color (bands 5,4,3) image of Lower Tasman Glacier from May 11th 2013. Red triangles denote GNSS installations. The location of the lake level sensor is shown by the green triangle. Inset map shows main figure location in red. 

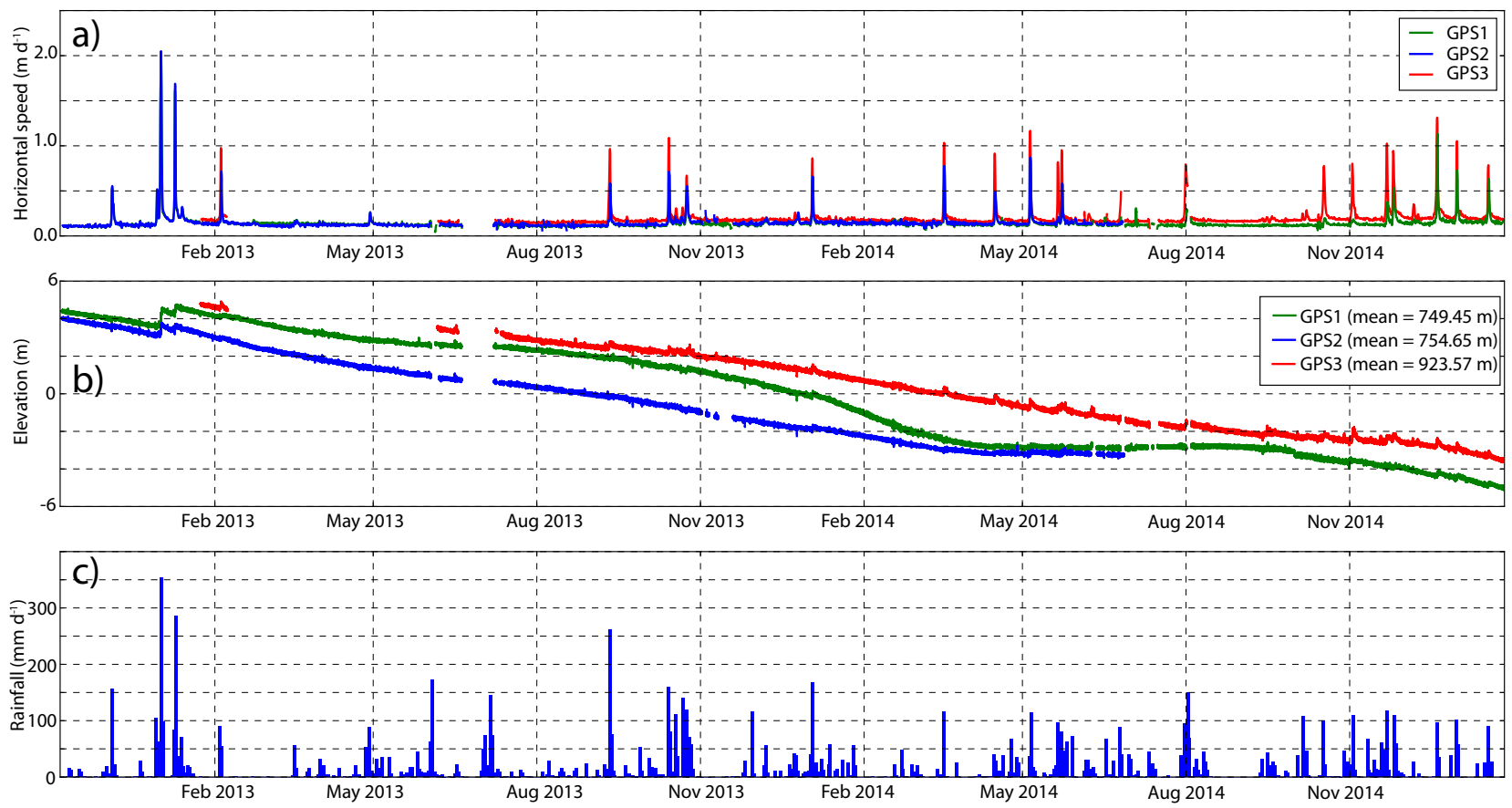

Figure 2: a) Tasman Glacier horizontal speed estimated hourly for all sites. Speed is calculated using 24-hour intervals. b) surface elevation every epoch (30 s) after the removal of mean value c) daily rain-rate recorded at Aoraki/Mt Cook Village. 

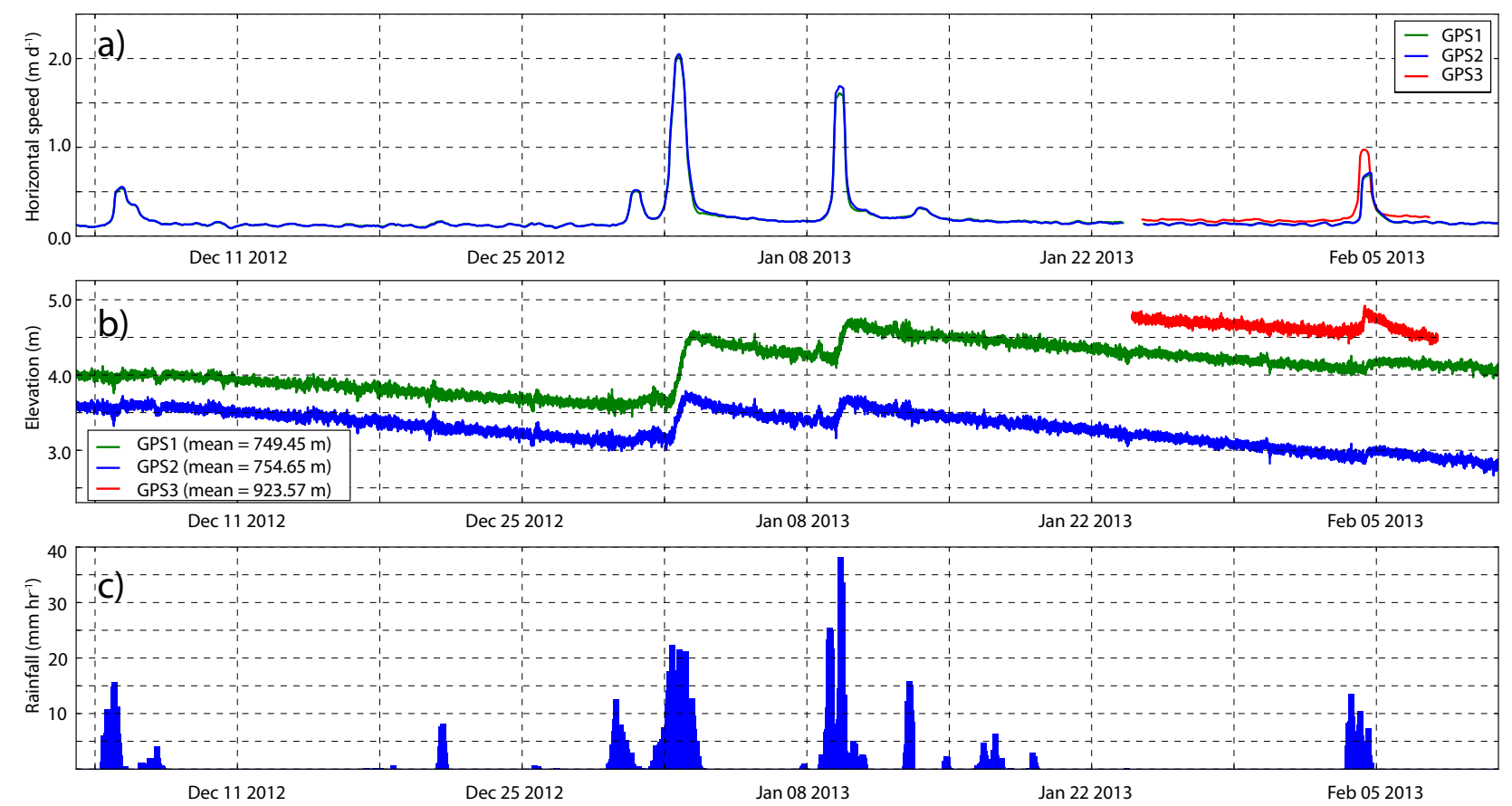

Figure 3: a) Tasman Glacier horizontal speed for all sites calculated over 24-hour intervals during the large rainfall events that occurred during late December 2012-early January 2013. b) surface elevation after the removal of mean values c) hourly rain rate recorded at Aoraki/Mt Cook Village. 


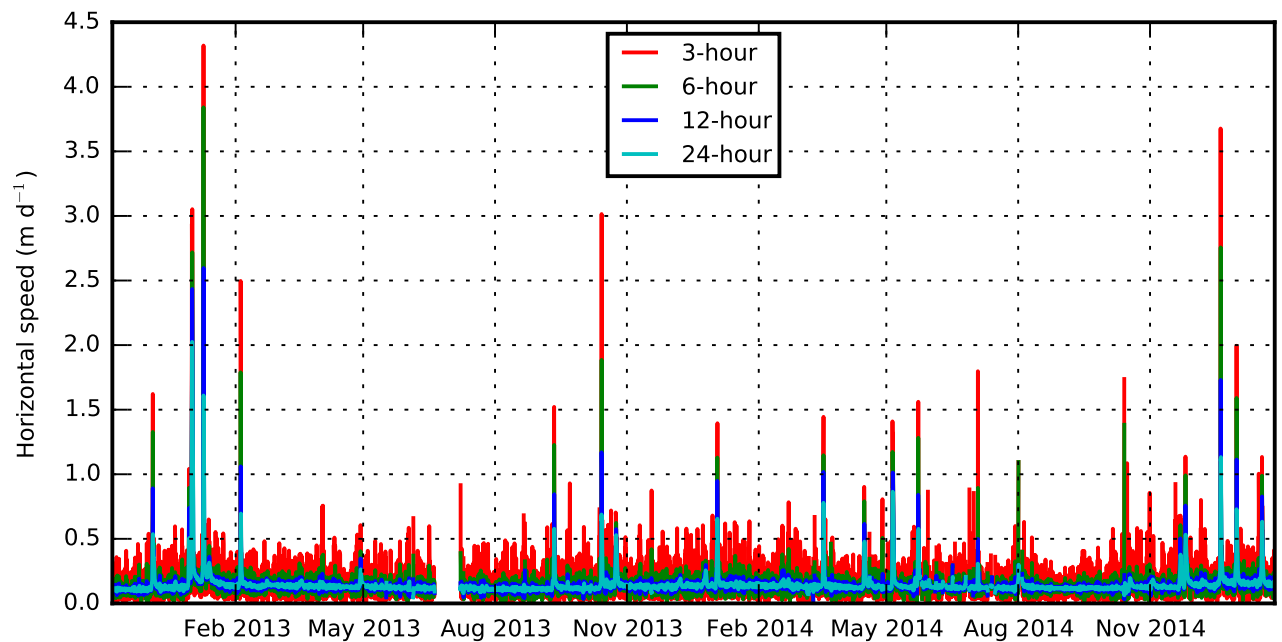

Figure 4: GPS1 speed calculated hourly from the gradients of linear regressions of twodimensional position within time intervals of 3-24 hr. 

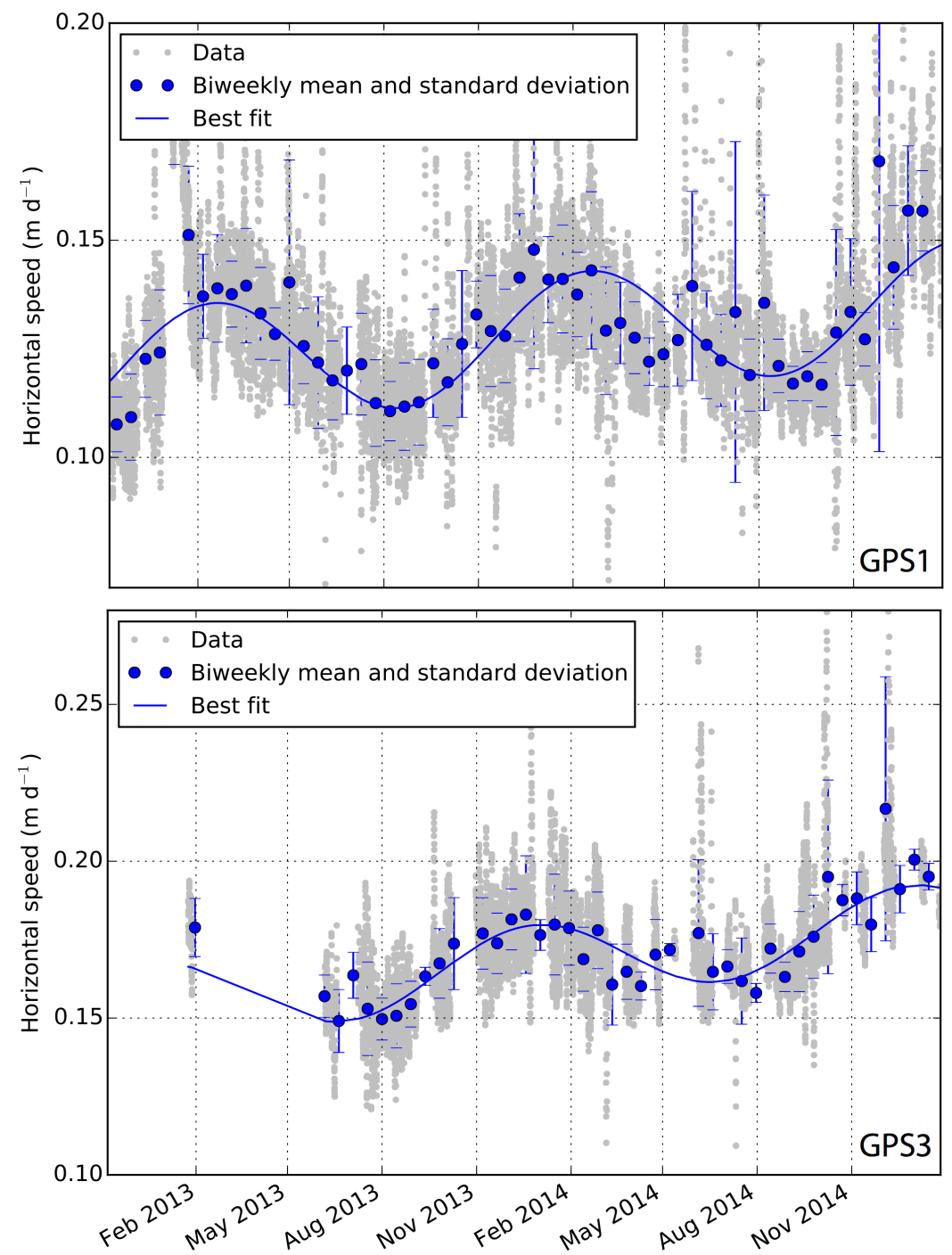

Figure 5: Grey dots show GPS1 24-hour speed after the editing of seven-day windows around each speed-up event. Blue line shows the best fitting $u=a \sin (\omega t+\phi)+b t+c$ function, where $u$ and $t$ denote speed and time, $\omega$ is determined by a period of one year, and $a, \phi, b$ and $c$ are optimized constants. Blue dots and error bars denote mean and standard deviation of speeds within two-we 2 bins. 

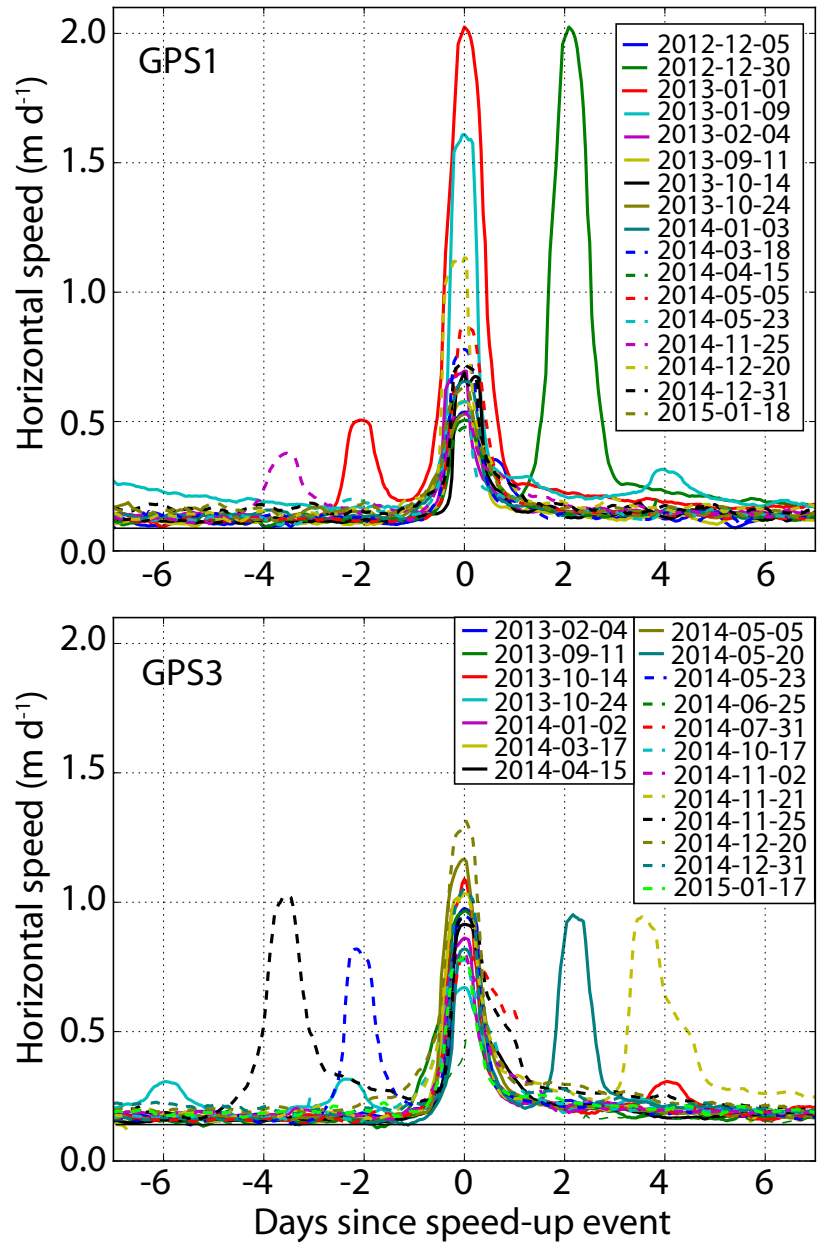

Figure 6: Top: GPS1 windowed speed-up events exceeding $0.4 \mathrm{~m} \mathrm{~d}^{-1}$. Bottom: GPS3 windowed speed-up events exceeding $0.4 \mathrm{~m} \mathrm{~d}^{-1}$. Thin black horizontal lines are included to emphasise the difference in velocity before and after the speed-up events. Note that the close proximity of events results in them being shown multiple times with a lagged offset. 

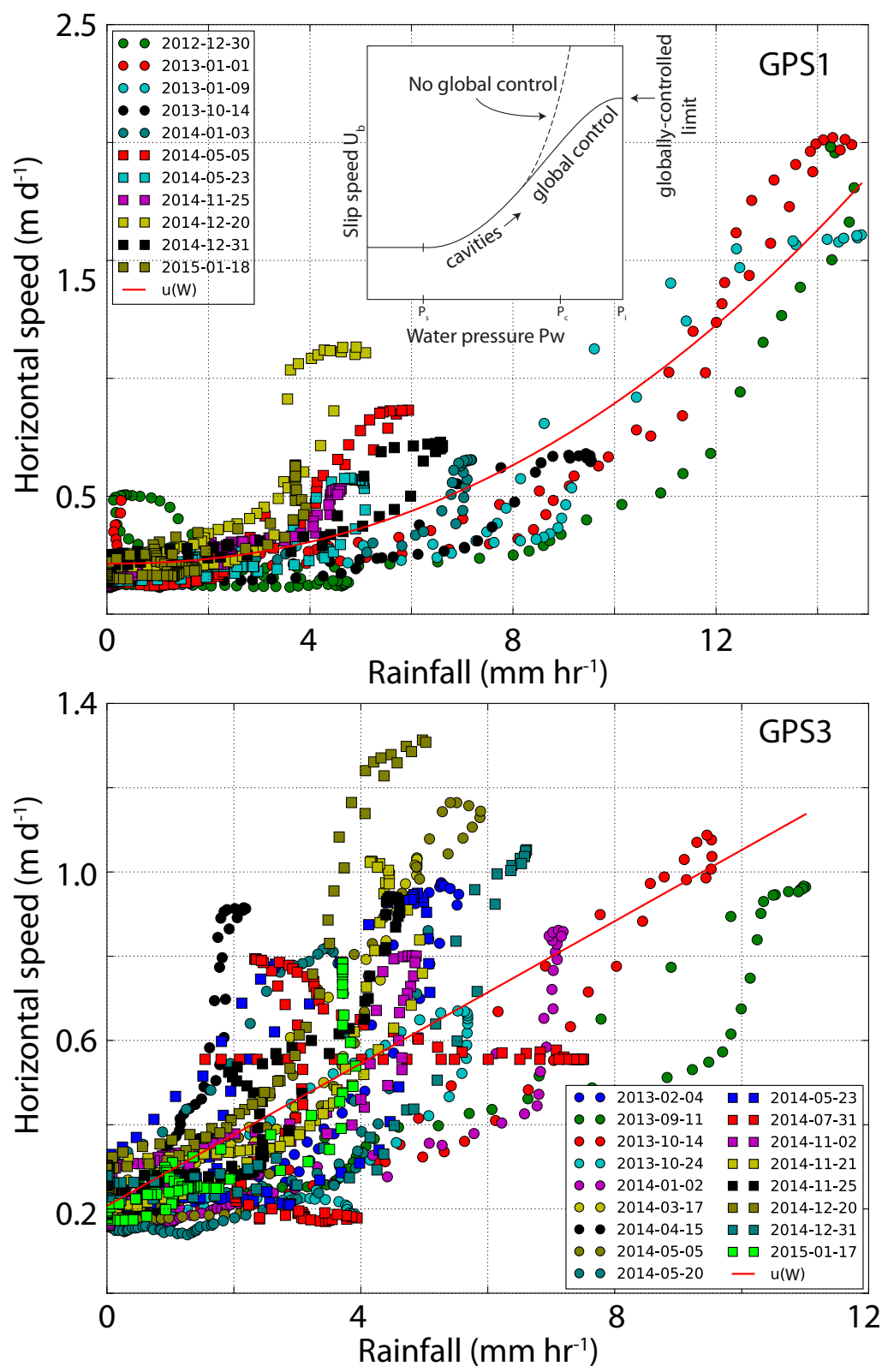

Figure 7: 24-hour speed plotted against filtered (24-hour running mean) hourly rain rate. Top panel: GPS1, red line shows optimal $u(W)=d W^{e}+f$, function. Inset shows schematic speed - water pressure relationship from Cuffey and Paterson (2010)). Bottom panel: GPS3, red line shows optimal $u(W)=d W+f$ function. 

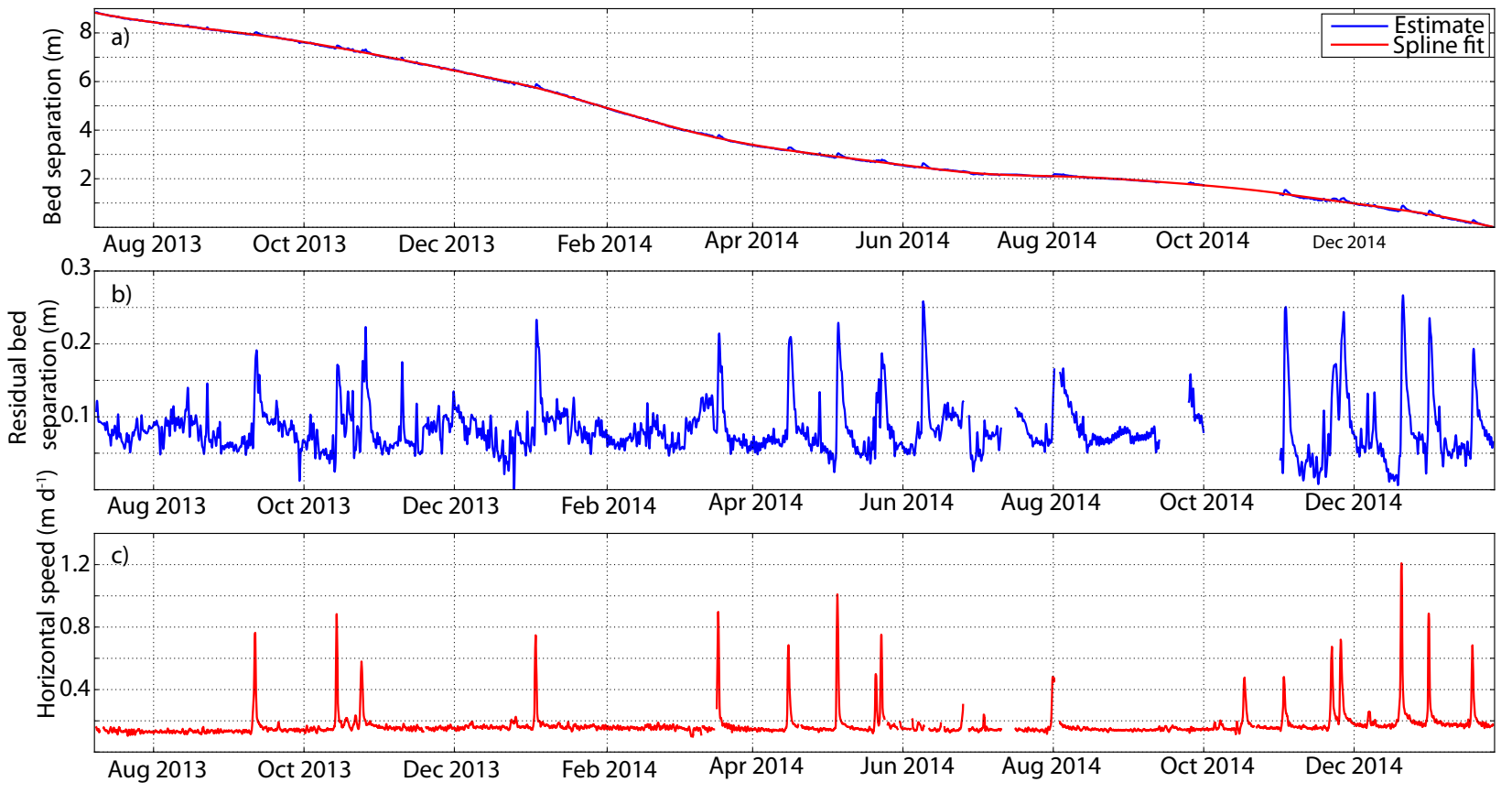

Figure 8: a) Bed separation estimated at the mid-point between GPS1 and GPS3 (blue) and best fitting spline (red). b) bed separation (blue line above) after the removal of the best fitting spline (red line above) and addition of a constant value to set the minimum residual to zero. c) average horizontal speed for GPS1 and GPS3. (Note that October 2014 bed separation estimate are missing due to the base station failure. 

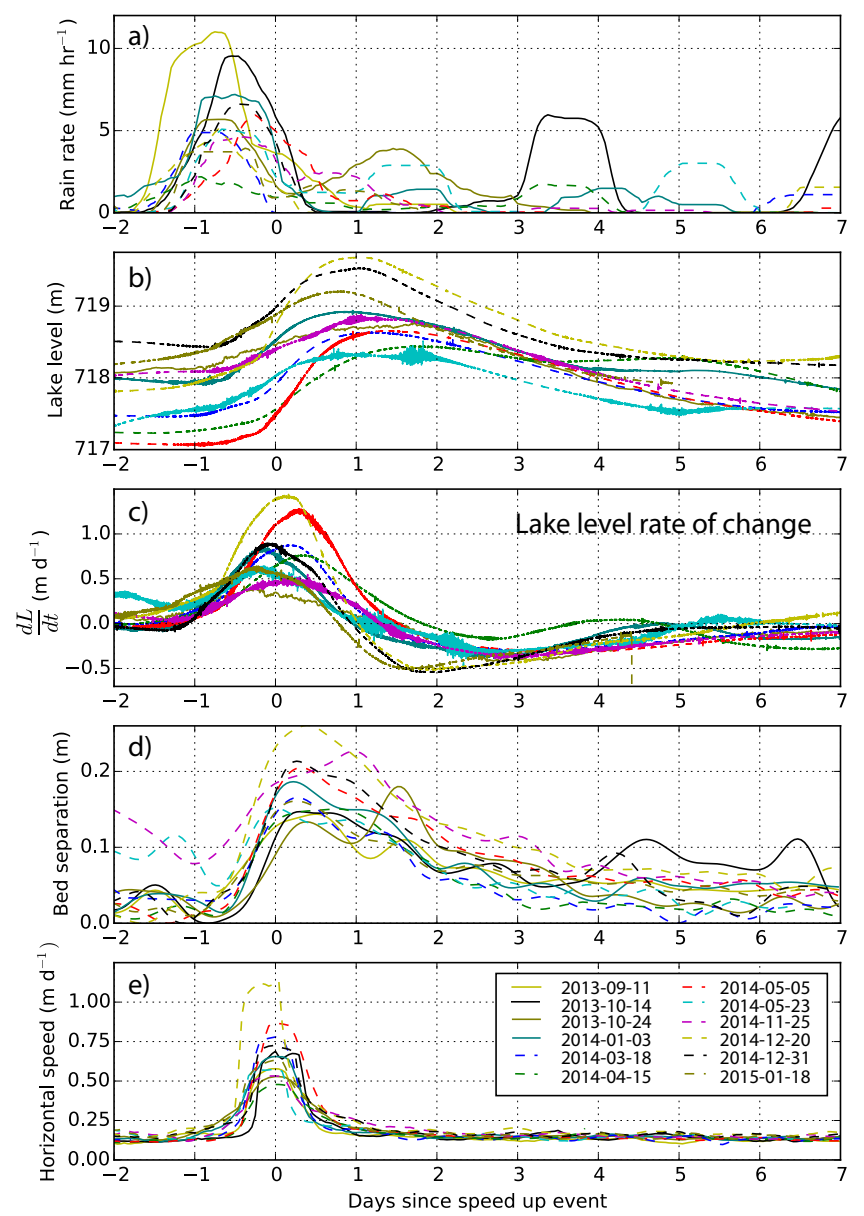

Figure 9: Windowed speed-up events for all GPS1 events exceeding $0.4 \mathrm{~m} \mathrm{~d}^{-1}$ for which bed separation estimates are available. a) Rain rate. b) Lake level. c) Lake level rate of change. d) Bed separation. e) Horizontal speed. Note that lake-level records are not available for the two earliest events shown. 


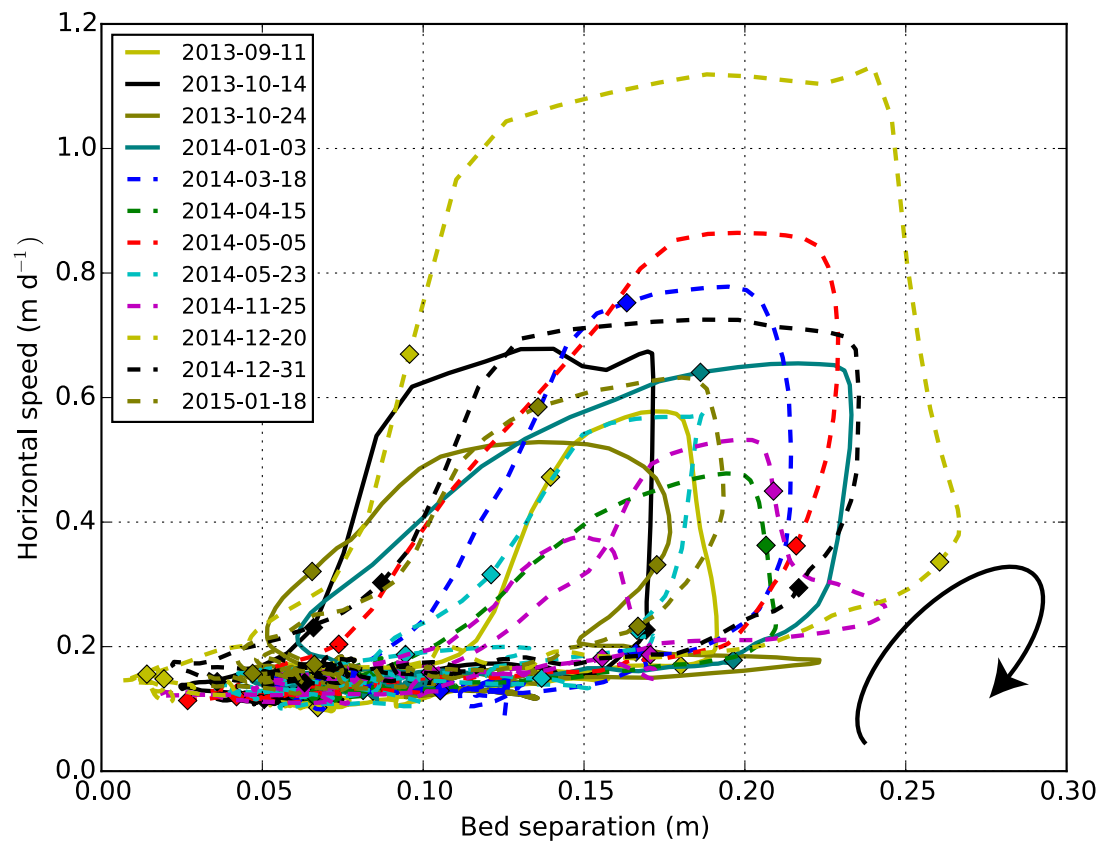

Figure 10: Bed separation versus speed for 14-day windows around all events exceeding $0.4 \mathrm{~m} \mathrm{~d}^{-1}$ for which bed separation estimates are available. Diamond markers indicate 24-hour intervals. All trajectories are clockwise as shown by arrow. 